\title{
Sex, Age, and Individual Differences in Bottlenose Dolphins (Tursiops truncatus) in Response to Environmental Enrichment
}

\author{
Holli C. Eskelinen ${ }^{1,2^{*}}$, Kelley A. Winship ${ }^{1,3}$ and Jill L. Borger-Turner ${ }^{1,2,4}$ \\ ${ }^{1}$ Dolphins Plus Oceanside \\ ${ }^{2}$ Dolphins Plus Bayside \\ ${ }^{3}$ University of Southern Mississippi \\ ${ }^{4}$ University of Miami \\ *Corresponding author (Email: holli@dolphinsplus.com)
}

Citation - Eskelinen, H. C., Winship, K. A., \& Borger-Turner, J. L. (2015). Sex, age, and individual differences in bottlenose dolphins (Tursiops truncatus) in response to environmental enrichment. Animal Behavior and Cognition, 2(3), 241-253. doi: 10.12966/abc.08.04.2015

\begin{abstract}
Application of environmental enrichment, as a means to successfully decrease undesired behaviors (e.g., stereotypic) and improve animal welfare, has been documented in a variety of zoological species. However, a dearth of empirical evidence exists concerning age, sex, and individual differences in response to various types of enrichment tools and activities in Atlantic bottlenose dolphins (Tursiops truncatus). This study involved a comparative assessment of enrichment participation of three resident, bottlenose dolphin populations, over the course of 17 months, with respect to sex and age class (calf, sub-adult, adult). Enrichment sessions were randomly assigned, conducted, and categorically assessed based on participation during seven, broad based enrichment classes (Object, Ingestible, Human, or a combination of the three). Overall, the proportion of participation in enrichment sessions was high $(\geq 0.74)$, with individual differences in participation noted among the three populations. Sessions involving Humans and/or Ingestible items resulted in a significantly higher mean proportion of participation. Subadult and adult males were significantly more likely to participate in enrichment sessions, as well as engage in Human Interaction/Object sessions. Calves participated significantly more than adults or sub-adults across all enrichment classes with no noted differences between males and females. These data can serve as a tool to better understand the intricacies of bottlenose dolphin responses to enrichment in an effort to develop strategic enrichment plans with the goal of improving animal well-being and welfare.
\end{abstract}

Keywords - Enrichment, Tursiops truncatus, Bottlenose dolphin, EEDs, Welfare

Environmental enrichment in zoological facilities is considered essential to animal welfare (e.g., Clegg, Borger-Turner, \& Eskelinen, in press; Mellen \& Macphee, 2001) and involves the addition of supplemental stimuli to animals' environments that enhances biological, physiological, and psychological welfare (e.g., Kuczaj, Lacinak, \& Turner, 1998; Shepherdson, Mellen, \& Hutchins, 1998). Enrichment has been shown to increase neural performance in cognitive tasks (van Praag, Kempermann, \& Gage, 2000) and decrease the rehearsal of stereotypic behaviors, which are suggested to be a derivative of sterile or unstimulating environments, fear, stress, and/or frustration (Mason, 1991; Tan et al., 2013), and can be reduced with the strategic implementation of applied environmental enrichment (e.g., Shyne, 2006). However, empirical evidence is lacking concerning whether certain activities or objects are enriching to bottlenose dolphins, and, on the contrary, Environmental Enrichment Devices (EEDs) may be aversive, futile, and ineffective, producing unintended and potentially unfavorable outcomes (e.g., avoidance, aggression) (e.g., Delfour \& Beyer, 2012; Hoy, Murray, \& Tribe, 2010). Therefore, a better understanding 
of sex, age, and individual differences in response to applied enrichment, and efforts to identify the reinforcement value of enrichment tools through empirical studies (e.g., Galef, 1999; Hoy et al., 2010), is critical to successful animal management plans. While enrichment likely occurs while animals are under stimulus control (e.g., during husbandry training sessions) (Laule \& Desmond, 1998; Pomerantz \& Terkel, 2009; Swaisgood \& Shepherdson, 2005), the implementation of supplemental enrichment, occurring outside of stimulus control scenarios, is the focus of most related studies.

The use of objects as a source of environmental enrichment has been universally applied in zoos and aquaria. For example, feeding enrichment has been utilized with large mammals, such as primates (Brent \& Eichberg, 1991; Reinhardt, 1993), felids (Bashaw, Bloomsmith, Marr, \& Maple, 2003), giraffes (Giraffa camelopardalis; Fernandez, Bashaw, Sartor, Bouwens, \& Maki, 2008), and ursids (Carlstead, Seidensticker, \& Baldwin, 1991). During enrichment sessions, food is often hidden in the enclosure or encased in ice or a feeding device, thus requiring the animals to exert energy to find and consume their food (Hoy et al., 2010). Other common objects utilized as enrichment include "toys", or structural objects, and studies of human children and animals have indicated sex and age related differences is response to specific objects, often referred to as "preferences", as well as individual differences. For example, sex differences in toy interests are apparent in human children: males show preferences toward toys characterized by motion (e.g., trucks, airplanes), and females favor plush toys (e.g., dolls) (Connor \& Serbin, 1977; Liss, 1981). Some suggest early toy preferences may hint at a predisposition for a particular gender role (e.g., Alexander, 2003), likely shaped by culturally driven reinforcement histories, and the possible influence of gonadal hormones during important developmental stages (Berenbaum \& Hines, 1992; Collaer \& Hines, 1995). In non-human species, significant differences in male versus female interactions and engagement with objects have been identified in rhesus monkeys (Macaca mulatta: Hasset, Siebert, \& Wallen, 2008), vervet monkeys (Cercopithecus aethiops sabaeus: Alexander \& Hines, 2002), and orange-winged Amazon parrots (Amazona amazonica: Webb, Famula, \& Millam, 2010).

Preferential object play among dolphins has been documented in both wild (Connor et al., 2000; Kuczaj \& Highfill, 2005; Kuczaj \& Yeater, 2006; Mann \& Smuts, 1999; Silva, Silva, \& Sazima, 2005; Würsig, 2002), and captive populations (Kuczaj \& Eskelinen, 2014; Kuczaj \& Highfill, 2005; Kuczaj \& Walker, 2012; Paulos, Trone, \& Kuczaj, 2010). Captive bottlenose dolphins (Tursiops truncatus) and free ranging Atlantic spotted dolphins (Stenella frontalis) played with objects more frequently alone, as opposed to with others, and captive animals residing in sea-pens were more likely to interact with local flora and fauna than their wild counterparts (Greene, Mellilo-Sweeting, \& Dudzinski, 2011). Dolphin calves have also been noted to participate in creative play behaviors, with peers increasing the propensity toward novel interactions (Kuczaj, Makecha, Trone, Paulos, \& Ramos, 2006). Although trends in sex differences in response to enrichment objects have been identified in bottlenose dolphins (e.g., Clark, Davies, Madigan, Warner, \& Kuczaj, 2013; Greene et al., 2011; von Streit \& Ganslosser, 2013), conclusive evidence has been limited by sample size.

Age is also suggested to play a role in enrichment interactions in different species. Young chimpanzees were noted to interact with environmental enrichment more frequently than older chimpanzees, but all preferred to interact with items that were destructible (Videan, Fritz, Schwandt, Smith, \& Howell, 2005). Among walrus (Odobenus rosmarus divergens) calves, feeding enrichment was found to occupy a large portion of their time, and older calves spent more time manipulating devices that involved fish inside ice than younger animals (Kastelein, Jennings, \& Postma, 2007). However, van Praag et al. (2000) suggested that older animals still experience neurological benefits of enrichment, even when their interactions with enrichment may not be as frequent as younger individuals. Age differences in dolphin object play have been described in observational studies (e.g., von Streit \& Ganslosser, 2013), and the effectiveness of familiar objects applied as enrichment items was also explored with dolphins, revealing some individual preferences and varying levels of interaction (Delfour \& Beyer, 2012).

Dolphins have been noted to exhibit an increase in play behaviors following Dolphin-Human Interaction programs, which suggests that interacting with humans is enriching or reinforcing (Trone, Kuczaj, \& Solangi, 2005). Although documented in other species such as chimpanzees (Pan troglodytes: Baker, 2004), stump-tailed macaques (Macaca arctoides: Waitt, Buchanan-Smith, \& Morris, 2002), and 
other primates (Prescott \& Buchanan-Smith, 2003), there is a paucity of literature regarding the use of humans and human interaction as part of a strategic enrichment plan outside of training scenarios. In this study, a large and diverse population of bottlenose dolphins was studied over the course of 17 months in an effort to document sex, age, and individual animal responses to specific enrichment tools and sessions, including objects, ingestible items, and humans.

\section{Method}

\section{Subjects}

The animals observed in this study included 19 Atlantic bottlenose dolphins (Tursiops truncatus) (Table 1) housed at Dolphins Plus Oceanside, Dolphins Plus Bayside, and Island Dolphin Care in Key Largo, Florida. Dolphins Plus Oceanside and Island Dolphin Care's lagoons (total area of $1,672 \mathrm{~m}^{2}$ and a mean depth of $3.6( \pm 1.2) \mathrm{m})$ are separated by a public-access canal, adjacent to the Atlantic Ocean. Dolphins Plus Bayside is located on the Florida Bay and consists of a $1,858 \mathrm{~m}^{2}$ area with an approximate mean depth of $5.4( \pm 1.2) \mathrm{m}$. Animals were divided into age classes based on reproductive history: adults reproductive, sub-adults - independent but not sexually mature, and calves - dependent and nursing. Two of the Tursiops calves evaluated in the study were born midway through the project (see Table 1).

Table 1

Demographics of the Study Population. Two Animals (Isaac and Baby Bit) were born during the Study

\begin{tabular}{|c|c|c|c|}
\hline Name & Sex & Date of Birth & Age Class \\
\hline Isaac & $\mathrm{M}$ & $6 / 1 / 11$ & Calf \\
\hline Baby Bit & $\mathrm{F}$ & $9 / 13 / 11$ & Calf \\
\hline Grace & $\mathrm{F}$ & $7 / 11 / 08$ & Calf \\
\hline Lotus & F & $8 / 27 / 08$ & Calf \\
\hline Zoe & $\mathrm{F}$ & $7 / 14 / 10$ & Calf \\
\hline Elvis & $\mathrm{M}$ & $8 / 5 / 04$ & Sub-adult \\
\hline Fiji & $\mathrm{M}$ & $6 / 25 / 04$ & Sub-adult \\
\hline Leo & M & $7 / 29 / 03$ & Sub-adult \\
\hline Bella & $\mathrm{F}$ & $11 / 3 / 00$ & Sub-adult \\
\hline Julie & $\mathrm{F}$ & $8 / 19 / 07$ & Sub-adult \\
\hline Nica & $\mathrm{F}$ & $6 / 2 / 04$ & Sub-adult \\
\hline Alfonz & M & $7 / 25 / 93$ & Adult \\
\hline Bob & M & $7 / 28 / 94$ & Adult \\
\hline Kimbit & M & $8 / 27 / 93$ & Adult \\
\hline Dinghy & $\mathrm{F}$ & e 1977 & Adult \\
\hline Jessica & F & e 1984 & Adult \\
\hline Samantha & F & e 1984 & Adult \\
\hline Sarah & $\mathrm{F}$ & e 1984 & Adult \\
\hline Squirt & $\mathrm{F}$ & e 1982 & Adult \\
\hline
\end{tabular}

e estimated year of birth 


\section{Procedure}

Enrichment sessions were randomly assigned and conducted a minimum of once every other week at varying times of the day during non-interaction periods at each facility from March 2011 to August 2012. As described by Mellen and MacPhee (2001), independent observers systematically rated the intensity of individual interactions during each session and in response to each type of enrichment (i.e., no participation, participation, significant participation), noting the time of day and duration of the enrichment session, for a total of 353 trials. Individual participation was defined as interaction (i.e., tactile or visual) during an enrichment session for greater than $10 \%$ of the duration of the session, whereas significant participation constituted greater than $50 \%$ of participation during the session. For all analyses, the overall participation data were defined as the proportion of the population that interacted. Additional fine scale analyses were performed on the proportion of participation for each age class $(n=3)$ and sex $(n$ $=2$ ) during enrichment sessions.

Given the quantity of enrichment items and activities (including various combinations therein) utilized during the study $(n=198)$, enrichment was broadly defined and characterized by three, main classes: Human Involvement, Ingestible, and Object (Table 2). Human involvement required animal care members to be active participants in the enrichment session (e.g., visual and/or tactile interactions), further characterized by being in or out (e.g., on the dock) of the water. Ingestible enrichment included the introduction of fish, gelatin, or ice. Object enrichment sessions, involving Environmental Enrichment Devices (EEDs), were further characterized by three subcategories of structural, non-training related items (e.g., floating mats, buoy), structural, training related objects (e.g., hoop, pole), or organic/environmental objects (e.g., palm fronds, water from a hose). Enrichment sessions could include multiple classes of enrichment (e.g., human involvement and ingestible), and such sessions were analyzed as combined classes.

Table 2

Environmental Enrichment Classes, including Number of Trials per Class (and proportion of total trials), and Subcategories Utilized for Analysis

\begin{tabular}{llll}
\hline $\begin{array}{c}\text { Enrichment Class } \\
\text { (Operational Definition) }\end{array}$ & $\begin{array}{c}\text { Number of Trials } \\
\text { (Proportion of Total } \\
\text { Enrichment Trials) }\end{array}$ & \multicolumn{1}{c}{ Subcategories } & Example(s) \\
\hline $\begin{array}{l}\text { Human Interaction (Human } \\
\text { interaction only; no EEDs) }\end{array}$ & $n=23(0.06)$ & $\begin{array}{l}\text { Humans on the dock } \\
\text { Humans in the water }\end{array}$ & $\begin{array}{l}\text { Rubs from the dock } \\
\text { Swimming with mask, fins } \\
\text { around the lagoon }\end{array}$ \\
$\begin{array}{l}\text { Ingestible (Consumable } \\
\text { items only) }\end{array}$ & $n=27(0.07)$ & Ingestible items & Fish, gelatin, ice, fishcicles \\
$\begin{array}{l}\text { Object (EEDs only; humans } \\
\text { absent from the lagoon } \\
\text { area) }\end{array}$ & $n=88(0.24)$ & $\begin{array}{l}\text { Structural (non-training } \\
\text { session) item }\end{array}$ & $\begin{array}{l}\text { Hose, bubbles, buoys, } \\
\text { textured gloves, pool } \\
\text { noodles, floating mats } \\
\text { Hoop, pole, balls, rings }\end{array}$ \\
\hline
\end{tabular}


Table 2 (cont.)

Human Interaction/ Ingestible Items (Ingestible items delivered in varying ways from humans)

$$
n=15(0.04)
$$

Humans in or out of the water with ingestible items

Humans tossing fish/ice from side of lagoon
Human Interaction/Object (Humans actively participating with EEDs)

$$
n=162(0.45)
$$$$
n=162(0.45)
$$

(n)

Ingestible/Object (EEDs with ingestible items inside the object)

$$
\begin{aligned}
& n=13(0.03) \\
& n=25(0.07)
\end{aligned}
$$
Ingestible/Object (EEDs and ingestible items delivered by humans)
Humans in or out of the water with structural, training, or organic objects

Ingestible items accompanied with or within an object

Humans in or out of the water with ingestible items and structural, training, or organic objects
Humans tossing balls around the lagoon

\section{Cognitive based feeder} puzzles
Humans kayaking around the lagoon while tossing fish and ice

\section{Results}

The mean proportion of dolphins that participated during applied enrichment sessions, including all subjects and enrichment classes, was 0.74. Among enrichment classes, those that involved ingestible items, humans, and complex combinations were most frequently attended to (Figure 1). There was a significant difference in the mean proportion of participation, for all subjects combined $(n=19)$ and across all trials $(n=353)$, among enrichment classes (Brown-Forsythe: $F(6,346)=8.643, p<0.001$ ). Post hoc analyses revealed a significantly lower proportion of animals participating during Object sessions $(M=0.6364, S E=0.0299)$ compared to Ingestible $(M=0.8224, S E=0.0371$; Games-Howell: $p$ $<0.01)$, Human Interaction/Object $(M=0.7725, S E=0.0192 ; p<0.01)$, Ingestible/Object $(M=0.9295$, $S E=0.0376 ; p<0.001)$ and Human Interaction/Ingestible/Object sessions $(M=0.8791, S E=0.0348 ; p<$ 0.001) (Figure 1).

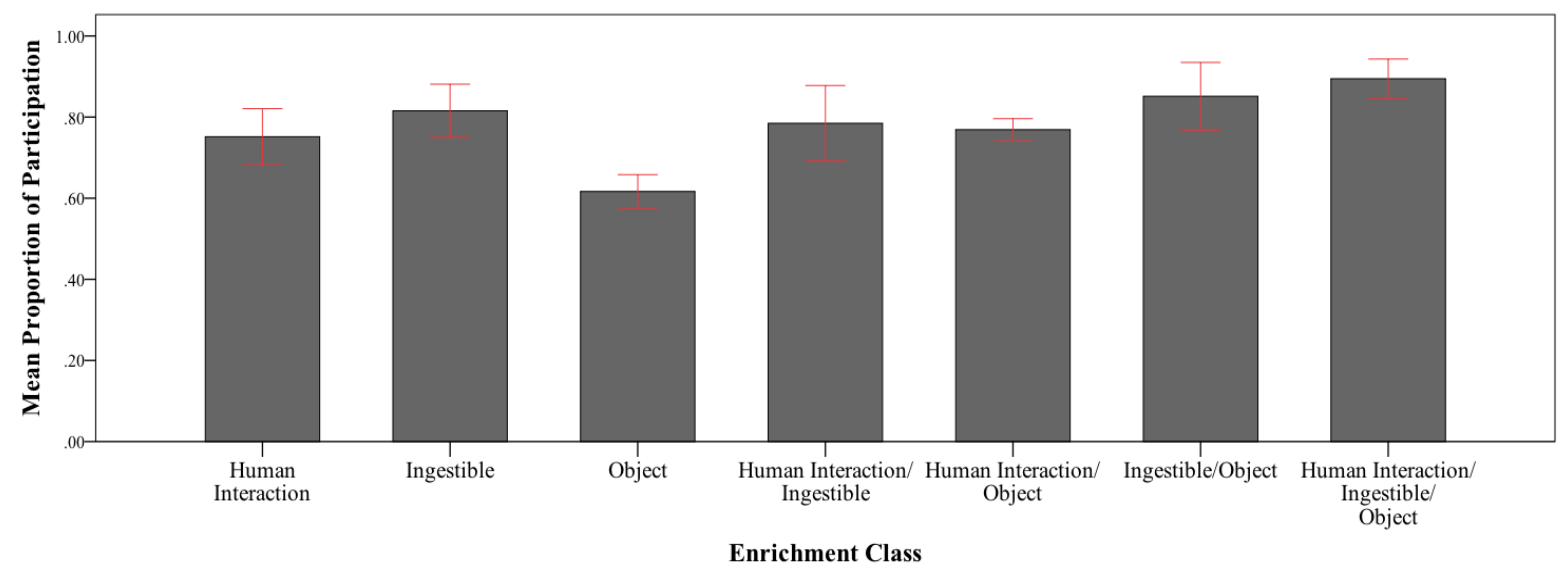

Figure 1. Mean $( \pm 2 \mathrm{SE})$ proportion of subjects $(n=19)$ that participated with each enrichment class, including all trials and subjects. A lower proportion of animals participated with Object enrichment compared to Ingestible $(p<0.01)$, Human Interaction/Object $(p<0.01)$, Ingestible/Object $(p<0.001)$ and Human Interaction/Ingestible/Object $(p<0.001)$ enrichment. 
A significantly greater proportion of animals participated during sessions when human interaction $(M=0.785, S E=0.0156)$ was involved compared to sessions without human interaction $(M=0.705, S E=$ $0.0241), t(351)=-2.89, p<0.004$ (Figure 2), as well as during sessions when ingestible items were present $(M=0.8425, S E=0.0187)$ compared to sessions without ingestible items $(M=0.722, S E=$ $0.01075) t(657.48)=-5.57, p<0.05$ (Figure 3). However, there was no significant difference in the proportion of animals that participated during object sessions $(M=0.747, S E=0.015)$ compared to nonobject sessions $(M=0.796, S E=0.0259), t(351)=1.40, p=0.163$.

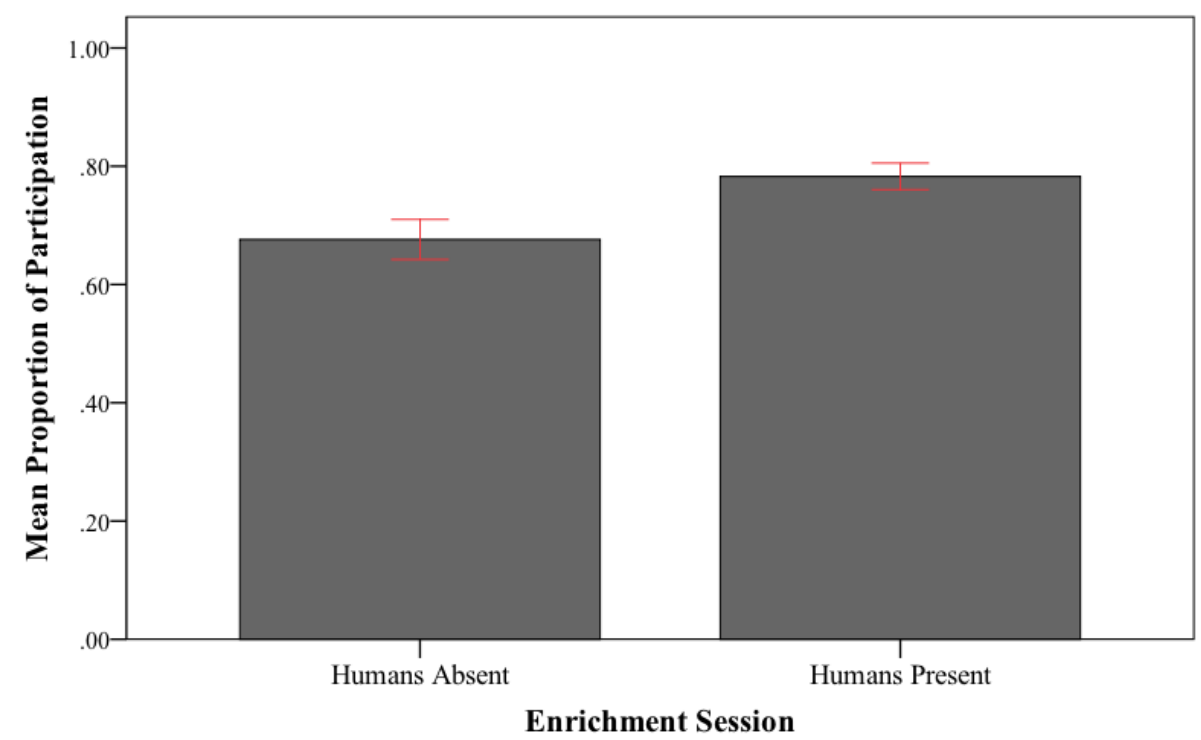

Figure 2. Mean $( \pm 2 \mathrm{SE})$ proportion of subjects $(n=19)$ that participated with human involvement enrichment classes versus nonhuman involvement classes, including all trials and subjects $(p<0.05)$.

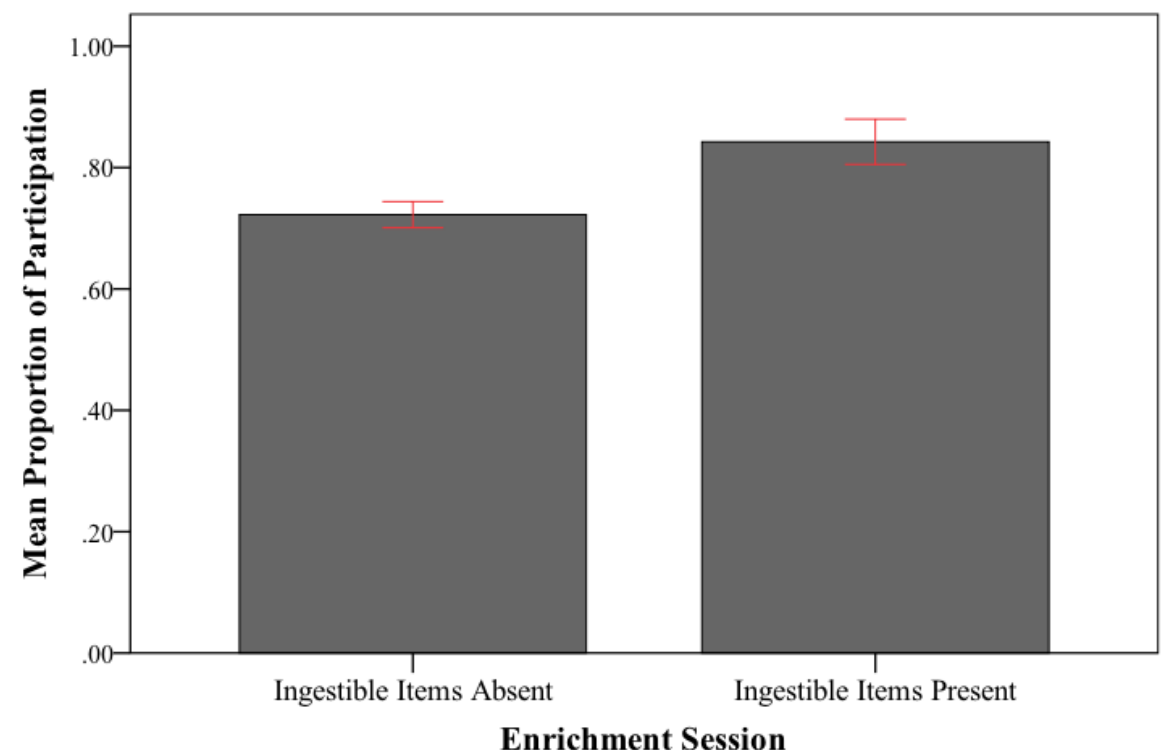

Figure 3. Mean $( \pm 2 \mathrm{SE})$ proportion of subjects $(n=19)$ that participated with ingestible enrichment classes versus non-ingestible classes, including all trials and subjects $(p<0.05)$. 
Overall, males $(M=0.7834, S D=0.0191)$ participated in more enrichment sessions than females $(M=0.7007, S D=0.0179)$ (Figure 4). There was a significant association between the sex of the animals and whether they were categorized as participating across all enrichment conditions $\left(\chi^{2}(1)=18.852, p<\right.$ 0.001). Based on the odds ratio, the odds of a male participating during an enrichment session was 1.611 times greater when compared to females. In the Human Interaction/Object condition, there was a significant relationship between sex and participation $\left(\chi^{2}(1)=18.474, p<0.001\right)$, with males being 2.05 times more likely to participate in this condition than the females. Significant relationships were not identified in the Human Interaction, Ingestible, or Object enrichment classes.

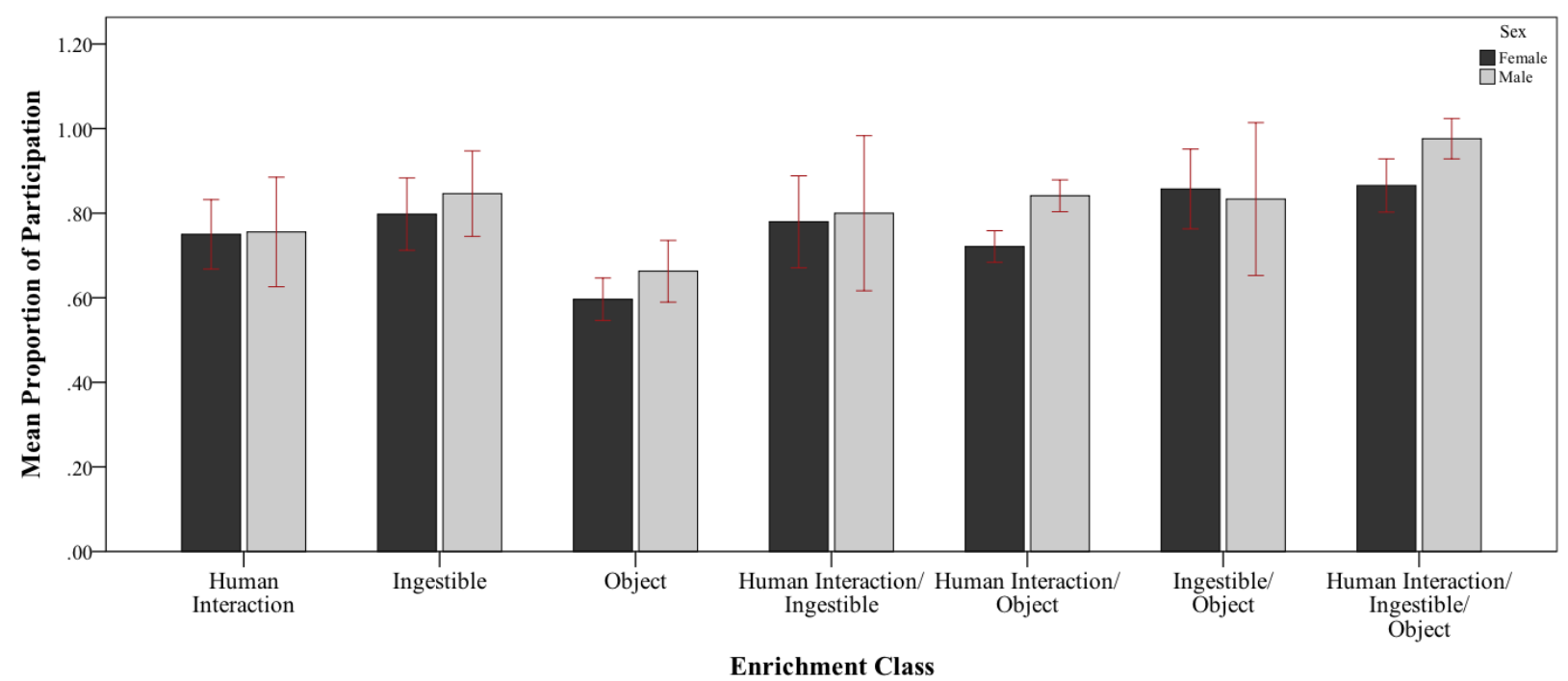

Figure 4. Mean $( \pm 2 \mathrm{SE})$ proportion of males $(n=7)$ and females $(n=12)$ that participated with each enrichment class, including all trials and subjects.

\section{Age Class}

The proportion of subjects participating in enrichment sessions was calculated for each enrichment and age class (i.e., calf, sub-adult, adult) (Figure 5). When analyzing all trials and all enrichment classes together, calves participated significantly more frequently during enrichment sessions than both sub-adult and adult animals (Brown Forsythe: $F(2,1751.46)=10.29, p<0.05$ ).

Differences between sexes within age classes were also examined. For adults, there was a significant relationship between sex and participation across enrichment classes $\left(\chi^{2}(1)=26.39, p<\right.$ 0.001), with males being 2.413 times more likely to participate in enrichment sessions than females. Similarly, sub-adult males were 1.563 times more likely to participate in enrichment sessions $\left(\chi^{2}(1)=\right.$ 26.39, $p<0.01)$ when compared to sub-adult females. There was no significant relationship between these two variables among calves.

Among individuals, there was a significant difference in the mean proportion of participation in all trials and enrichment classes combined (Brown-Forsythe $F(18,1632.25)=14.45, p<0.05)$. Post hoc analyses revealed no significant differences in the proportion of participation between mothers and their respective calves, except for Squirt/Lotus, in which Lotus participated more frequently with enrichment than Squirt $(p<0.05)$. Additionally, Jessica and Sam exhibited significantly less participation during enrichment sessions than all other adult females $(p<0.05)$. Nica and Fiji participated with enrichment significantly less than all other sub-adults $(p<0.05)$, and of the two calves born during the study, Isaac's proportion of participation was significantly higher than that of Baby Bit $(p<0.05)$ (Figure 6). 


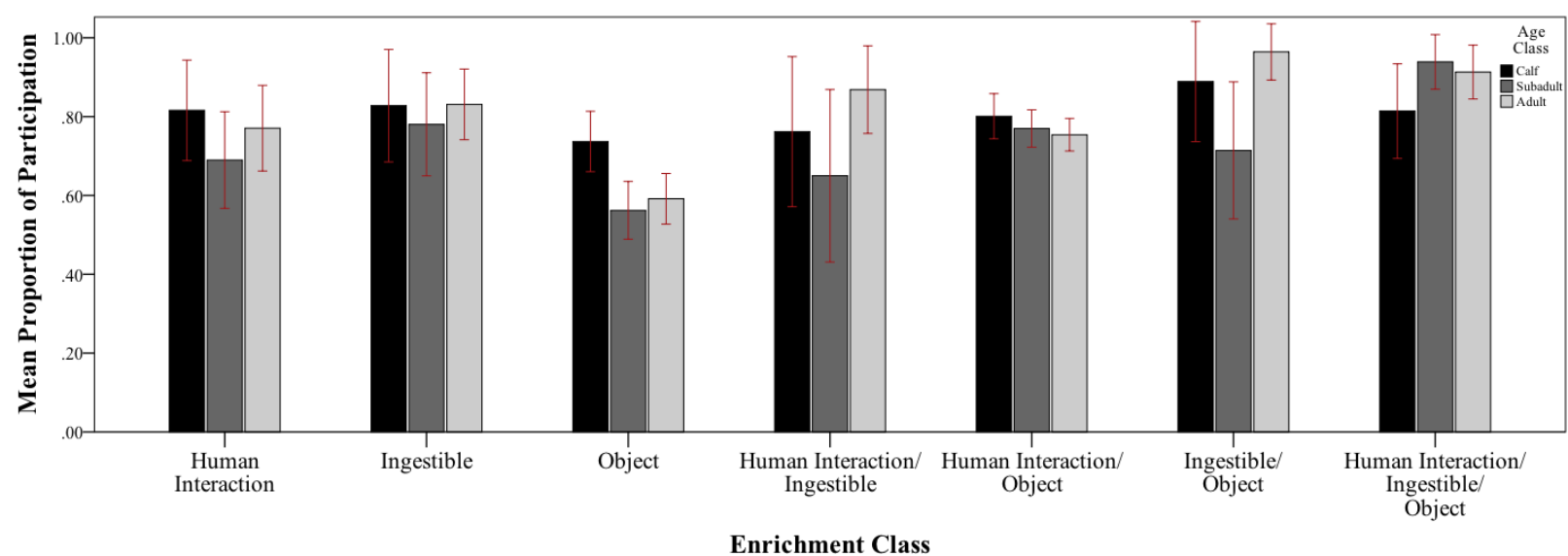

Figure 5. Mean $( \pm 2 \mathrm{SE})$ proportion of calves $(n=5)$, sub-adults $(n=6)$, and adults $(n=8)$ that participated with each enrichment class, including all trials and subjects.

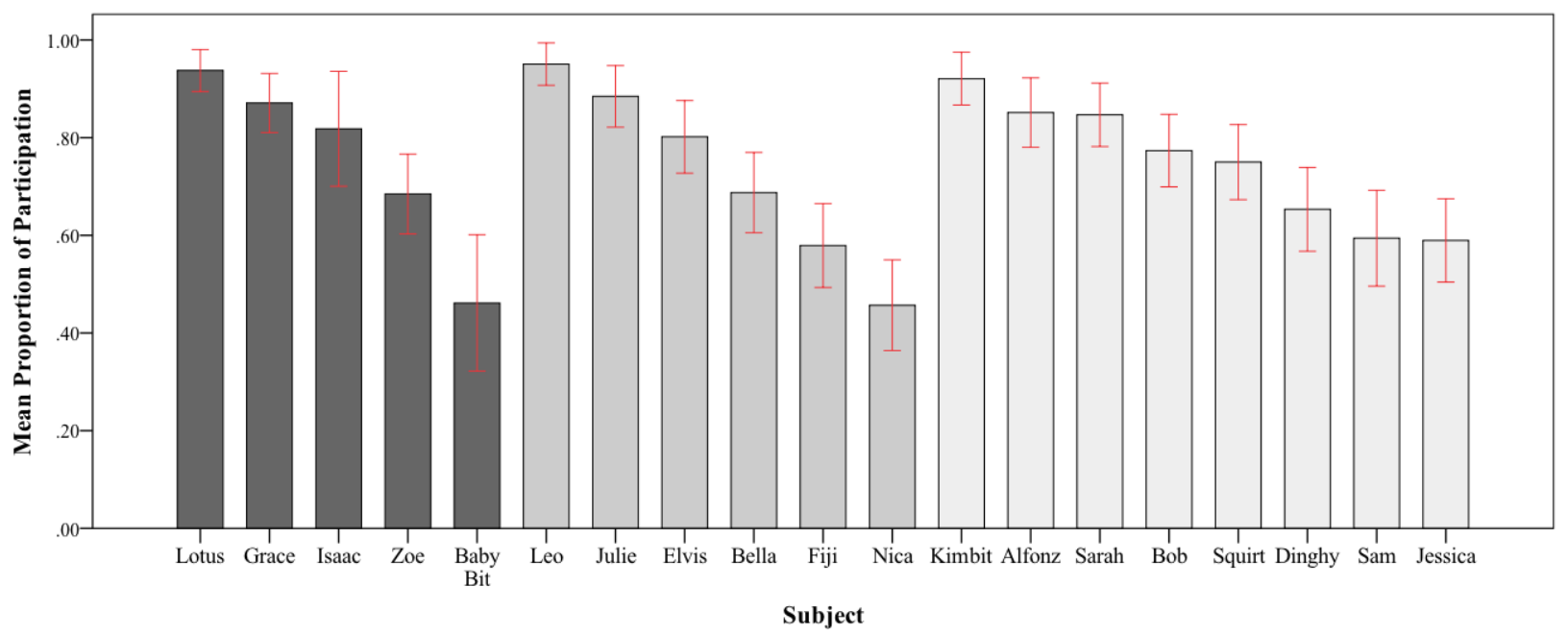

Figure 6. Mean ( $\pm 2 \mathrm{SE})$ proportion of participation for each subject, including all trials and all enrichment classes. Age class is delineated by color: calves $=$ dark grey, sub-adults $=$ medium grey, and adults $=$ light grey .

\section{Discussion}

The principle objective when applying environmental enrichment in managed care is to improve animal welfare, as both psychological and physical well-being are crucial to animal health. Understanding how animals respond to various types of enrichment is critical to effective enrichment plans, including data on species, population, demographic, and individual differences. With these data, enrichment activities and tools can be strategically adapted to specific individuals and groups, with focused goals and measurable, desired outcomes. This study revealed sex, age, and individual differences in response to various types of enrichment among bottlenose dolphins.

Although well over half of the total population interacted with applied enrichment, regardless of type, enrichment classes that involved ingestible items and human involvement were associated with more participation than those that did not. These results are similar to those described for other mammal species, aquatic and terrestrial, in which animals exhibited a preference towards ingestible forms of enrichment (e.g., Hunter, Bay, Martin, \& Hatfield, 2002; Swaisgood et al., 2001). Comparatively, when objects were used as a source of enrichment in this study, there was significantly less participation, which 
may reflect the lack of complexity associated with typical enrichment objects (e.g., balls, hoops, swim noodles). Many of these objects are subjectively classified as "toys" and tend to become part of the daily environmental landscape in managed care. Research suggests that habituation to items makes them less effective as enrichment devices (Delfour \& Beyer, 2012; Kuczaj et al., 2002; Line \& Morgan, 1991; Maki \& Bloodsmith, 1989; Markowitz \& Aday, 1998; Schapiro, Bloomsmith, Suarez, \& Porter, 1996). Thus, the dynamic and variable nature of ingestible enrichment and human involvement, when compared to static objects, may explain why the most complex enrichment class, Human Interaction/Ingestible/Object, produced the highest mean proportion of participation. These findings further support the need for well planned enrichment efforts but should also encourage caretakers to be creative in terms of variation and complexity when applying enrichment in managed care.

Humans as a potential source of enrichment for animals (Trone et al., 2005) was also examined in this study by focusing on human-animal interactions outside of training scenarios. Significantly more participation occurred during sessions involving humans than not (regardless of the presence of food), thus supporting the ideology that animal care staff enhanced enrichment sessions and contributed to increased participation. With the inherent reinforcing value of animal care staff (e.g., Baker, 2004; Prescott \& Buchanan-Smith, 2003; Waitt et al., 2002), utilizing personnel to enhance enrichment sessions is another effective tool for bottlenose dolphin enrichment programs. The incorporation of personnel in the enrichment sessions allows for greater variability in the application of enrichment and potentially allows for immediate interpretation of session success and individual enrichment preferences by staff within a facility.

Overall, males participated significantly more often in all enrichment classes, excluding Ingestible/Object sessions, than females. These results are similar to a study of captive male dolphins that were noted to play with objects more often than females (Greene et al., 2011). Furthermore, Ingestible/Object enrichment typically consisted of cognitive based puzzle feeder EEDs, thus limiting the ability for numerous animals to participate with the apparatus during the session. The animal(s) that participated with the apparatus first were typically adult females, and they commonly occupied it for the duration of the enrichment session, potentially deterring less dominant animals from participating in the task. However, female dominance has not been universal in impacting sex related response to these types of feeding EEDs. In a cooperative study, two dominant male dolphins prevented other animals from interacting with a cooperative feeding device, though they would allow an adult female to co-feed after the fish was released (Kuczaj, Winship, \& Eskelinen, 2015).

When examining participation among the calves, no significant sex differences in response to enrichment were revealed for either general participation or significant participation. However, of the two calves that were born during the study, the male calf participated significantly more than the female calf during enrichment sessions. In a previous study of two bottlenose dolphin calves, no sex differences regarding participation were noted, though specific object preferences were present (von Streit, Ganslosser, \& von Fersen, 2013), suggesting that object preferences may be acquired over time (e.g., Kuczaj \& Eskelinen, 2014). Additionally, a small sample size may have limited interpretations in this study, as the calves were exposed to relatively few enrichment sessions before the conclusion of data collection (Isaac: 44; Baby Bit: 52) when compared to the other subjects. The presence of calves in the study may have contributed to the relatively higher overall participation in enrichment sessions among sub-adult and adult males versus females due to the social obligations of adult females with dependent calves $(n=5)$ (Gibson \& Mann, 2008). The importance of the mother-calf relationship was highlighted in this study in that most pairs did not differ significantly in their frequency of participation during enrichment sessions, except for Squirt and Lotus. It is possible that this variability could be related to parental style (Hill, Greer, Solangi, \& Kuczaj, 2007) or duration of relationship between mother and calf, and such possibilities warrant future investigation.

Each of the study subjects had been known to participate in various enrichment activities. However, regardless of sex or age class, individual variability was identified within the study. This is similar to a study of harbor (Phoca vitulina concolor) and gray (Halichoerus grypus) seals, which were noted to display some individual differences in their responses to and preferences of particular enrichment 
items, though a general inclination toward food-emitting items was identified (Hunter et al., 2002). One of the females in this study, Jessica, has impaired vision and participated in significantly fewer enrichment sessions when compared to other females. This suggests that animals with special needs should be considered separately when developing enrichment plans. Flexible and complex social structure, as well as maturation and environmental changes, may affect animal participation in enrichment sessions (e.g., Greene et al., 2011; Kuczaj et al., 2002, 2006). Additionally, the reinforcement history associated with each enrichment class likely played a role in the level of participation noted among individuals, but these data were not available during this study.

The systematic, variable schedule for enrichment sessions used in this study was an effective model for eliciting high levels of participation. The application of enrichment should be strategically implemented and unpredictable in its presentation, while being mindful of variability and reinforcement value (e.g., Clegg et al., in press; Delfour \& Beyer, 2012; Kuczaj \& Walker, 2012), in order to optimize the effectiveness of subsequent enrichment efforts and activities (Hill \& Broom, 2009; Hoy et al., 2010). Enrichment must also be applied strategically in efforts to reinforce desirable behaviors (e.g., pro-social, affiliative, calm) and avoid accidentally reinforcing undesirable behaviors (e.g., aggressive) (e.g., Kuczaj et al., 1998). Therefore, the timing of the presentation of enrichment is critical to sound animal management. Furthermore, object based enrichment sessions produced the lowest mean participation from all subjects, supporting the need to consistently vary the types of EEDs presented to the animals. An animals' previous reinforcement history with particular enrichment items will likely influence the future enriching qualities of the device (Mason, Clubb, Latham, \& Vickery, 2007). Thus, if an item is used regularly as a source of enrichment for a specific animal, without consistent reinforcement, it is possible that its efficacy in terms of enrichment could be significantly diminished. For example, during three of the 198 enrichment combinations, no participation was observed by any of the animals in the population. Two of the sessions involved familiar EEDs, suggesting that habituation to these devices had occurred, and their enrichment value had decreased. Delegating a reserve of EEDs that are discrete from daily training session "toys" and utilized only during enrichment sessions can assist with maintaining novelty and unpredictability (e.g., Kuczaj et al., 2002). Habituation to objects begins after the first exposure (e.g., Thieltges, Lemasson, Kuczaj, Boye, \& Blois-Heulin, 2011), and non-strategic schedules of reinforcement associated with those EEDs can further reduce their effectiveness. Future studies should explore the differences in interest level among bottlenose dolphins towards particular objects, as such preferences have been noted in other species (e.g., Alexander \& Hines, 2002; Hasset et al., 2008; Webb et al., 2010), or environment type (e.g., open versus closed systems). To further improve enrichment sessions, routinely measuring participation levels during the exposure will allow caretakers to determine when stimuli are no longer enriching or reinforcing. Understanding the intricacies of enrichment preferences, among males and females, animals of different ages, and among individuals, will contribute to improved welfare of animals in managed care.

\section{Acknowledgements}

The authors would like to express their gratitude to the Animal Care/Training staff at each of the facilities for their commitment of providing routine enrichment sessions and their precise record keeping throughout the years. Additionally, we are also grateful to Cassandra Edelman, Kimberly McCallister, and Jordan Wallin for discussions leading to investigating this topic.

\section{References}

Alexander, G. M. (2003). An evolutionary perspective of sex-typed toy preferences: Pink, blue, and the brain. Archives of Sexual Behavior, 32, 7-14.

Alexander, G. M., \& Hines, M. (2002). Sex differences in response to children's toys in nonhuman primates (Cercopithecus aethiops sabaeus). Evolution and Human Behavior, 23, 467-479.

Baker, K. C. (2004). Benefits of positive human interaction for socially-housed chimpanzees. Animal Welfare, 13, 
239-245.

Bashaw, M. J., Bloomsmith, M. A., Marr, M. J., \& Maple, T. L. (2003). To hunt or not to hunt? A feeding enrichment experiment with captive large felids. Zoo Biology, 22, 189-198.

Berenbaum, S. A., \& Hines, M. (1992). Early androgens are related to childhood sex-typed toy preferences. Psychological Science, 3, 203-206.

Brent, L., \& Eichberg, J. W. (1991). Primate puzzleboard: A simple environmental enrichment device for captive chimpanzees. Zoo Biology, 10, 353-360.

Carlstead, K., Seidensticker, J., \& Baldwin, R. (1991). Environmental enrichment for zoo bears. Zoo Biology, 10, 316.

Clark, F. E., Davies, S. L., Madigan, A. W., Warner, A. J., \& Kuczaj, S. A. (2013). Cognitive enrichment for bottlenose dolphins (Tursiops truncatus): Evaluation of a novel underwater maze device. Zoo Biology, 32 , 608-619.

Clegg, I. L. K., Borger-Turner, J. L., \& Eskelinen, H. C. (in press). C-Well: The development of a welfare assessment index for captive bottlenose dolphins (Tursiops truncatus). Animal Welfare.

Collaer, M. L., \& Hines, M. (1995). Human behavioral sex differences: A role for gonadal hormones during early development? Psychological Bulletin, 118, 55-107.

Connor, J. M., \& Serbin, L. A. (1977). Behaviorally based masculine- and feminine-activity-preference scales for preschoolers: Correlates with other classroom behaviors and cognitive tests. Child Development, 48, 14111416.

Connor, R. C., Wells, R. S., Mann, J., \& Read, A. J. (2000). The bottlenose dolphin. Cetacean societies, 91-125.

Delfour, F., \& Beyer, H. (2012). Assessing the effectiveness of environmental enrichment in bottlenose dolphins (Tursiops truncatus). Zoo Biology, 31, 137-150.

Fernandez, L. T., Bashaw, M. J., Sartor, R. L., Bouwens, N. R., \& Maki, T. S. (2008). Tongue twisters: Feeding enrichment to reduce oral stereotypy in giraffe. Zoo Biology, 27, 200-212.

Galef, B. G. Jr. (1999). Environmental enrichment for laboratory rodents: Animal welfare and the methods of science. Journal of Applied Animal Welfare Science, 2, 26-280.

Gibson, Q. A., \& Mann, J. (2008). Early social development in wild bottlenose dolphins: sex differences, individual variation and maternal influence. Animal Behaviour, 76(2), 375-387.

Greene, W. E., Melillo-Sweeting, K., \& Dudzinski, K. M. (2011). Comparing object play in captive and wild dolphins. International Journal of Comparative Psychology, 24, 292-306.

Hassett, J. M., Siebert, E. R., \& Wallen, K. (2008). Sex differences in rhesus monkey toy preferences parallel those of children. Hormones and Behavior, 54, 359-364.

Highfill, L. E., \& Kuczaj, S. A., II. (2007). Do bottlenose dolphins (Tursiops truncatus) have distinct and stable personalities. Aquatic Mammals, 33, 380-389.

Hill, S. P., \& Broom, D. M. (2009). Measuring zoo animal welfare: Theory and practice. Zoo Biology, 28, 531-544.

Hill, H. M., Greer, T., Solangi, M., \& Kuczaj, S. A. II. (2007). All mothers are not the same: Maternal styles in bottlenose dolphins (Tursiops truncatus). International Journal of Comparative Psychology, 20, 35-54.

Hoy, J. M., Murray, P. J., \& Tribe, A. (2010). Thirty years later: Enrichment practices for captive mammals. Zoo Biology, 29, 303-316.

Hunter, S. A., Bay, M. S., Martin, M. L., \& Hatfield, J. S. (2002). Behavioral effects of environmental enrichment on harbor seals (Phoca vitulina concolor) and gray seals (Halichoerus grypus). Zoo Biology, 21, 375-387.

Kastelein, R. A., Jennings, N., \& Postma, J. (2007). Feeding enrichment methods for Pacific walrus calves. Zoo Biology, 26, 175-186.

Kuczaj, S. A., \& Eskelinen, H. C. (2014). Why do dolphins play? Animal Behavior and Cognition, 1, $113-127$.

Kuczaj, S. A., \& Highfill, L. E. (2005). Dolphin play: Evidence for cooperation and culture? Behavioral and Brain Sciences, 28, 705-706.

Kuczaj, S., Lacinak, T., Otto, F., Trone, M., Solangi, M., \& Ramos, J. (2002). Keeping environmental enrichment enriching. International Journal of Comparative Psychology, 15, 127-137.

Kuczaj, S., Lacinak, C. T., \& Turner, T. (1998). Environmental enrichment for marine mammals at Sea World. In D. J. Shepherdson, J. D., Mellen, \& J. D., Hutchins, M. (Eds.), Second nature: Environmental enrichment for captive animals (pp. 314-328). Washington, DC: Smithsonian Institution Press.

Kuczaj, S. A., Makecha, R., Trone, M., Paulos, R. D., \& Ramos, J. A. A. (2006). Role of peers in cultural innovation and cultural transmission: Evidence from the play of dolphin calves. International Journal of Comparative Psychology, 19, 223-240.

Kuczaj, S. A., II, \& Walker, R. T. (2012). Dolphin problem solving. In T. Zentall \& E. Wasserman (Eds.), Handbook of comparative cognition (pp. 736-756). Oxford, UK: Oxford University Press. 
Kuczaj, S. A. II, Winship, K. A. \& Eskelinen, H. C. (2015). Can bottlenose dolphins (Tursiops truncatus) cooperate when solving a novel task? Animal Cognition, 18(2), 543-550.

Kuczaj, S. A., \& Yeater, D. B. (2006). Dolphin imitation: Who, what, when and why? Aquatic Mammals, 32, 413422.

Laule, G., \& Desmond, T. (1998). Positive reinforcement training as an enrichment strategy. In D. J. Shepherdson, J. D. Mellen, \& M. Hutchins (Eds.), Second nature: Environmental enrichment for captive animals (pp. 302313). Washington, DC: Smithsonian Institution Press.

Line, S. W., \& Morgan, K. N. (1991). The effects of two novel objects on the behavior of singly caged adult rhesus macaques. Laboratory Animal Science, 41, 365-369.

Liss, M. B. (1981). Patterns of toy play: An analysis of sex differences. Sex Roles, 7, 1143-1150.

Maki, S., \& Bloodsmith, M. A. (1989). Uprooted trees facilitate the psychological wellbeing of captive chimpanzees. Zoo Biology, 8, 79-87.

Mann, J., \& Smuts, B. (1999). Behavioral development in wild bottlenose dolphin newborns (Tursiops sp.). Behaviour, 136, 529-566.

Markowitz, H., \& Aday, C. (1998). Power for captive animals: Contingencies and nature. In D. J. Shepherdson, J. D., Mellen J. D., Hutchins, M. (Eds.), Second nature: Environmental enrichment for captive animals (pp. 47-58). Washington, DC: Smithsonian Institution Press.

Mason, G. J. (1991). Sterotypies: A critical review. Animal Behavior, 41, 1015-1037.

Mason, G., Clubb, R., Latham, N., \& Vickery, S. (2007). Why and how should we use environmental enrichment to tackle stereotypic behaviour?. Applied Animal Behaviour Science, 102(3), 163-188.

Mellen, J., \& Macphee, S. M. (2001). Philosophy of environmental enrichment: past, present, and future. Zoo Biology, 20, 211-226.

Paulos, R. D., Trone, M., \& Kuczaj, S. A. (2010). Play in wild and captive cetaceans. International Journal of Comparative Psychology, 23, 201-722.

Pomerantz, O., \& Terkel, J. (2009). Effects of positive reinforcement training techniques on the psychological welfare of zoo-housed chimpanzees (Pan troglodytes). American Journal of Primatology, 71(8), 687-695.

Prescott, M. J., \& Buchanan-Smith, H. M. (2003). Training nonhuman primates using positive reinforcement techniques. Journal of Applied Animal Welfare Science, 6, 157-161.

Reinhardt, V. (1993). Enticing nonhuman primates to forage for their standard biscuit ration. Zoo Biology, 12, 307312 .

Schapiro, S. J., Bloodsmith, M. A., Suarez, S. A., \& Porter, A. M. (1996). Effects of social and inanimate enrichment on the behavior of yearling rhesus monkeys. American Journal of Primatology, 40, 247-260.

Shepherdson, D. J., Mellen, J. D., \& Hutchins, M. (1998). Second nature: Environmental enrichment for captive animals. Washington, DC: Smithsonian Institution Press.

Shyne, A. (2006). Meta-analytic review of the effects of enrichment on stereotypic behavior in zoo mammals. Zoo Biology, 25, 317-337.

Silva-Jr., J. M., Silva, F. J. L., \& Sazima, I. (2005). Rest, nurture, sex, release, and play: Diurnal underwater behavior of the spinner dolphin at Fernando de Nornonha Archipelago, SW Atlantic. Journal of Ichthyology and Aquatic Biology, 9, 161-176.

Swaisgood, R. R., \& Shepherdson, D. J. (2005). Scientific approaches to enrichment and stereotypies in zoo animals: What's been done and where should we go next? Zoo Biology, 24, 499-518.

Swaisgood, R. R., White, A. M., Zhou, X., Zhang, H., Wei, R., ...Lindburg, D. G. (2001). A quantitative assessment of the efficacy of an environmental enrichment programme for giant pandas. Animal Behaviour, 61, 447457.

Tan, H. M., Ong, S. M., Langat, G., Bahaman, A. R., Sharma, R. S. K., \& Sumita, S. (2013). The influence of enclosure design on diurnal activity and stereotypic behaviour in captive Malayan Sun bears (Helarctos malayanus). Research in Veterinary Science, 94, 228-239.

Thieltges, H., Lemasson, A., Kuczaj, S., Boye, M., \& Blois-Heulin, C. (2011). Visual laterality in dolphins when looking at (un)familiar humans. Animal Cognition, 14, 303-308.

Trone, M., Kuczaj, S., \& Solangi, M. (2005). Does participation in dolphin-human interaction programs affect bottlenose dolphin behaviour? Applied Animal Behaviour Science, 93, 363-374.

van Praag, H., Kempermann, G., \& Gage, F. H. (2000). Neural consequences of environmental enrichment. Nature Reviews Neuroscience, 1, 191-198.

von Streit, C., \& Ganslosser, U. (2013). Behavioral development of two captive mother-calf dyads of bottlenose dolphins (Tursiops truncatus) in the calves' first year. International Journal of Comparative Psychology, 26, 176-196. 
von Streit, C., Ganslosser, U., \& von Fersen, L. (2013) Behavioral development of two captive mother-calf dyads of bottlenose dolphins (Tursiops truncatus) in the calves' first year. International Journal of Comparative Psychology, 26(3), 176-196.

Videan, E. N., Fritz, J., Schwandt, M. L., Smith, H. F., \& Howell, S. (2005). Controllability in environmental enrichment for captive chimpanzees. Journal of Applied Animal Welfare Science, 8, 117-130.

Waitt, C., Buchanan-Smith, H. M., \& Morris, K. (2002). The effects of caretaker-primate relationships on primates in the laboratory. Journal of Applied Animal Welfare Science, 5, 309-319.

Webb, N. V., Famula, T. R., \& Millam, J. R. (2010). The effect of rope color, size, and fray on environmental enrichment device interaction in male and female orange-winged Amazon parrots (Amazona amazonica). Applied Animal Behaviour Science, 124, 149-156.

Würsig, B. (2002). Playful behavior. In W. F. Perrin, B. Würsig, \& J. G. M. Thewissen (Eds.), Encyclopedia of marine mammals (pp. 943-945). San Diego: Academic Press. 